\title{
Effects of Single and Repeated Phencyclidine Administration on the Expression of Metabotropic Glutamate Receptor Subtype mRNAs in Rat Brain
}

Shuzo Abe, M.D., Toshihito Suzuki, M.D. Ph.D. Takehiko Ito, M.D. PhD Mika Yamaguchi, Atsuomi Baba, M.D., Ph.D., Takafumi Hori, M.D., Ph.D., Hirofumi Kurita, M.D., Hiroyasu Shiraishi, M.D., Ph.D. and Nobuo Okado, M.D., Ph.D.

Recent animal studies regarding phencyclidine (PCP), which induces psychotic symptoms in humans, have suggested that group II metabotropic glutamate receptors ( $m$ GluRs) represent a novel target for the treatment of PCP psychosis. In the present study, we used in situ hybridization to investigate the gene expressions of the $m G l u R$ 1-5 subtypes following single and repeated administration of $P C P$ in rats. A single administration of $P C P(7.5 \mathrm{mg} / \mathrm{kg}$, i.p., $)$ resulted in a significant decrease in the $m G$ GLR 5 mRNA expression of group I $m G$ GluR in the subcortical regions (thalamus $(-15 \%)$, central gray $(-23 \%)$, inferior colliculus $(-23 \%)$, and nucleus accumbens $(-10 \%))$ and hippocampal formation (CA1 $(-14 \%), C A 2(-15 \%), C A 3(-18 \%)$, and dentate gyrus $(-18 \%))$. After repeated PCP administration for 14 days, the $m$ GluR2 $m R N A$ expression of group II $m G l u R$ in the anterior cingulate cortex (-23\%) and the mGluR4 mRNA expression of group III $m$ GluR in the cortical regions (parietal $(-11 \%)$, temporal $(-13 \%)$ and entorhinal cortices $(-18 \%))$, the caudate putamen $(-12 \%)$, thalamus $(-17 \%)$, and subiculum ( $-25 \%)$ were significantly decreased. These results indicate that PCP affects not only group II $m G$ GluR but also group I and III of $m G l u R$, and it is of particular interest that $m G$ GluR2 subtype is involved in a development of behavioral abnormality following repeated PCP administration. Single and repeated administrations of $P C P$ independently regulate the expression of $m G l u R$ subtypes of $m R N A$ in the brain.

[Neuropsychopharmacology 25:173-184, 2001] (C) 2001 American College of Neuropsychopharmacology. Published by Elsevier Science Inc.
From the Department of Psychiatry, Institute of Clinical Medicine (SA, TS, MY, AB, TH, HK, HS), Neurobiology Laboratory, Department of Anatomy (NO), Institute of Basic Medical Science, University of Tsukuba, 1-1-1 Tennodai, Tsukuba, Ibaraki 305-8575, Faculty of Education, University of Okayama (TI), 3-1-1 Tsushimanaka, Okayama, Okayama 700-8530, Japan

Address correspondence to: Toshihito Suzuki, M.D., Ph.D., Department of Psychiatry, Institute of Clinical Medicine, University of Tsukuba, 1-1-1 Tennoudai, Tsukuba, Ibaraki 305-8575, Japan. Tel. and Fax: +81-298-53-3180, E-mail: psuzukit@md.tsukuba.ac.jp

Received June 12, 2000; revised November 25, 2000; accepted November 30, 2000.
KEY WORDS: Metabotropic glutamate receptor; Phencyclidine; NMDA antagonist; Glutamate; Schizophrenia; In situ hybridization

PCP, a non-competitive N-methyl-D-aspartate (NMDA) receptor antagonist, induces a psychotomimetic state that has been suggested to be the best pharmacological model of schizophrenia (Javitt and Zukin 1991; Jentsch and Roth 1999). Experimental animals have shown increased locomotor activity and stereotyped behaviors after a single injection of PCP (Sturgeon et al. 1979; Castellani and Adams 1981), and a sensitization phenomenon to the drug and cognitive disruption after consecu- 
tive injections (Nabeshima et al. 1987; Jentsch et al. 1997). Previous reports have suggested that these actions of PCP have been responsible for the alterations of both central nervous neurotransmitter systems (both receptors and transmitter release, including glutamate, dopamine, serotonin, and [ $\gamma$-amino-butyric acid (GABA)]. Research into the mechanism by which PCP induces psychosis in humans and abnormal behaviors in rodents is currently quite active, and may provide valuable findings underlying the development of new antipsychotic drugs and may enhance our understanding of the pathophysiology of PCP psychosis and schizophrenia.

Recent animal studies regarding PCP have suggested that group II mGluR receptors represent a novel target for the treatment of PCP psychosis (Moghaddam and Adams 1998; Cartmell et al. 1999, 2000). The family of mGluRs mediates their actions in central nervous system (CNS) via activation of G-proteins and the subsequent induction of second messenger transduction pathways (Conn and Pin 1997). To date, several cDNAs encoding mGluRs have been characterized and classified into three subgroups based upon receptor pharmacology and their coupling to intracellular second messenger pathways (Conn and Pin 1997). Group I mGluRs (mGluR1 and mGluR5) are coupled to phospholipase C activation and modulate glutamate excitability primarily via postsynaptic mechanisms (Nicoletti et al. 1996; Manzoni et al. 1997). Other groups including the group II mGluRs (mGluR2 and mGluR3) and group III mGluRs (mGluR4, mGluR6, mGluR7, and mGluR8) are coupled negatively to adenylate cyclase (Nicoletti et al. 1996; Conn and Pin 1997). Both the group II and group III mGluRs have been implicated in the modulation of glutamate neural transmission by predominantly presynaptic mechanisms (Nicoletti et al. 1996; Conn and Pin 1997). As well, selective agonists for groups II and III mGluRs have been shown to decrease the evoked release of glutamate in vitro in synaptosomes (East et al. 1995) and brain slices (Di Iorio et al. 1996), as well as in vivo microdialysis (Battaglia et al. 1997; Cozzi et al. 1997), and produce presynaptic inhibitory effects at certain glutamate synapses in electrophysiological studies (Lovinger and McCool 1995; Martin et al. 1997). Previously accumulated knowledge of the properties of these receptors in the CNS suggests that they could be candidates for novel drug targets in psychiatric and neurological disorders (Nicoletti et al. 1996; Moghaddam and Adams 1998).

Recently, Moghaddam and Adams (1998) reported that LY354740, as a selective group II mGluR agonist, blocked PCP-evoked increases of glutamate level in prefrontal cortex and nucleus accumbens, while having no effects on basal or PCP-evoked extracellular dopamine levels (Moghaddam and Adams 1998). This effect of LY354740 was associated with reductions in PCPevoked locomotor activity and the inhibition of PCPinduced stereotyped behaviors. Subsequently, another group demonstrated that selective group II mGluR agonists, such as LY354740 and LY379268, inhibited PCPevoked behaviors in a dose-dependent manner, but had minimal effects on d-amphetamine-evoked motor activities (Cartmell et al. 1999, 2000). Furthermore, the inhibition of PCP response by LY379268 was completely reversed by a selective group II mGluR antagonist LY341495 (Cartmell et al. 1999). These data indicate that the group II mGluR agonists may block PCP-mediated behaviors via a novel mechanism (reduction in PCPevoked glutamate release), which might be independent of the dopaminergic system.

Although several reports have demonstrated that PCP induces enhanced extracellular glutamate levels, which are reversed by a selective group II mGluR agonist, in the rat (Adams and Moghaddam 1998; Moghaddam and Adams 1998), the effects of PCP on mGluRs have never been examined. To date, the regional dysfunctional ideas suggesting the pathophysiology of schizophrenia and/or psychosis induced by NMDA antagonists have been presumed in the abnormal function of one or another brain region, like the cortex (Weinberger et al. 1992; Tamminga 1998), hippocampus (Heckers et al. 1998; Csernansky et al. 1998), thalamus (Carlsson and Carlsson 1990) and striatum (Stevens 1973). The glutamatergic system is organized into an ascending neuronal system, whose axons rise out of the hippocampal complex and extend up to the basal ganglia and the cingulate cortex, and a descending neuronal system, whose axons extend from the neocortex down to the subcortical structure (Greenamyre and Porter 1994). Thus, in the present article, we used in situ hybridization to investigate whether the levels of mRNA for mGluR 1-5 are modulated by single and repeated PCP administration in the specific brain regions of rat.

\section{MATERIALS AND METHODS}

\section{Chemicals}

$\left[\alpha^{35} \mathrm{~S}\right]$ dATP $(1250 \mathrm{Ci} / \mathrm{mmol})$, Nensorb 20 nucleic acid purification cartridges, and terminal transferase were purchased from New England Nuclear (Boston, MA). Oligonucleotide probes were synthesized from Nissinbo Co. Ltd.(Tokyo, Japan). PCP was gifted from Taisho Pharmaceutical Co., Ltd. (Tokyo, Japan). All other chemicals were obtained from commercial sources.

\section{Animal Treatment}

Male Wistar rats weighing 260-300g were used for all experiments. The animals were maintained under a 12hr light/12-hr dark cycle with food and water available ad libitum. All experiments were conducted in a hu- 
mane manner, according to the Japanese Governmental Law No. 105 and the University of Tsukuba's Regulations of governing Animal Experiments. Animals received daily intraperitoneal (i.p.) injections with saline or PCP $(7.5 \mathrm{mg} / \mathrm{kg})$ for one day or 14 days. Rats were sacrificed by decapitation one hour after a single injection or 24 hours after the last injection of repeated treatment.

Furthermore, as a control study, we also prepared decapitated rats 24 hours after a single injection of PCP or saline to examine the effects of single PCP administration on long-term neurochemical changes. The brains were rapidly dissected and frozen in liquid nitrogen. Horizontal section was cut in a cryostat, thaw mounted onto gelatine-coated slides at $-20^{\circ} \mathrm{C}$, and stored at $-80^{\circ} \mathrm{C}$ for further analysis.

\section{Behavioral Analysis}

Behavioral experiments were conducted between 2 and 6 P.M. on the 1st, 5 th, 10th, and 14th days at room temperatures of $22-24^{\circ} \mathrm{C}$. Rats were placed individually into test cages $(35 \times 35 \times 25 \mathrm{~cm}$ high). After allowing one hour of familiarization with the test conditions, each rat was treated with PCP $(7.5 \mathrm{mg} / \mathrm{kg}$, i.p.) or saline, and its locomotor activities and stereotyped behaviors were then measured for one hour. Locomotor activities were automatically measured using SUPERMEX, (Muromachi Kikai Co., Ltd., Tokyo, Japan). The ambulation was scored by using a personal computer interfaced to the rat body temperature-sensitive sensors. To examine PCP-induced stereotyped behaviors, videotaped recordings of the behavior of PCP-treated rats were also made. Next, the stereotyped behaviors were rated by trained observers into the following categories: rearing (the number of times the animal stood on its hind legs), backpedaling (the number of times the animal exhibited backward locomotion). The ratings were obtained for 60 minutes. The animals in the behavioral experiment were used in further in situ hybridization.

\section{In situ Hybridization}

In situ hybridization was carried out according to our previous report with minor modifications (Abe et al. 2000). Oligonucleotide probes (45 mers) with sequences complimentary to five subtypes (mGluR1-5) were used in the present study, according to previous reports (Testa et al. 1994; Fotuhi et al. 1994). To examine the cytoarchitectonic effects of PCP, we also performed a hybridization of gene expression for a cytoskeleton, $\beta$-actin (Ponte et al. 1984). The subtype specificity of the probes, the probe sequences, and the base regions encoded by the cDNAs to which they were made are as follows: mGluR1, 5'-CCC CAC GTG GAC ATA GTC ATA GCG ATT AGC TTC TGT GTA CTG CAG, Base No. 18261870, mGluR2, 5'-GGT GAC AGC TGT AGG AGC ATC
ACT GTG GGT GGC ATA GGA GCC ATC, Base No. 558-602, mGluR3, 5'-CTG AGA ATA GGT GGT TGC AGT TCC GCT GAC GCT GAA CCT GTT GAG, Base No. 2662-2706, mGluR4, 5'-GGT CTC CAG GTT CTC ACA CAG CTC TGA TTT GGC TTC CCC ATT GGG, Base No. 3495-3539, mGluR5, 5'-GGA GCG GAA GGA AGA AGA TCC ATC TAC ACA GCG TAC CAA ACC TTC, Base No. 637-681, $\beta$-actin, 5'-GGC TGG GGT GTT GAA GGT CTC AAA CAT GAT CTG GGT CAT C, Base No. 394-434 (Ponte et al. 1984). The probe was labeled on its $3^{\prime}$ end using terminal deoxynucleotidyl transferase and $\left[\alpha^{-35}\right.$ S ]dATP. Next, 10 picomoles of probe in tailing buffer $(0.1 \mathrm{M}$ potassium cacodylate, $25 \mathrm{mM}$ Tris base, $1.0 \mathrm{mM}$ cobalt chloride, and $0.2 \mathrm{mM}$ dithiothreitol, $\mathrm{pH} 7.0)$ and $50 \mathrm{pmol}\left[\alpha_{-}{ }^{35} \mathrm{~S}\right] \mathrm{dATP}$ were incubated in the presence of 72 units of terminal deoxynucleotidyl transferase at $37^{\circ} \mathrm{C}$ for 45 minutes. The reaction was terminated by Nensorb-20 column chromatography. The labeled probe was eluted in $50 \%$ ethanol. The probe solution was diluted with a hybridization buffer ( $50 \%$ formamide, 10\% dextran sulfate, 1\% Denhardt's solution, $100 \mathrm{mM}$ dithiothreitol, $0.025 \%$ tRNA from Escherichia coli, and $0.05 \%$ DNA from salmon testes in $4 \times$ sodium chloride-sodium citrate buffer $(\mathrm{SSC})(1 \times \mathrm{SSC}=0.15 \mathrm{M} \mathrm{NaCl}$ and $15 \mathrm{mM}$ sodium citrate, $\mathrm{pH}$ 7.0). Final radioactivity of the hybridization solution was approximately $2 \times 10^{4} \mathrm{dpm} / \mu \mathrm{l}$.

Tissue sections were fixed prior to hybridization. The sections were sequentially immersed at room temperature according to the following procedure: $4 \%$ paraformaldehyde and $0.02 \%$ diethylpyrocarbonate in $0.1 \mathrm{M}$ phosphate buffered saline adjusted to 7.4 for 10 minutes, $0.1 \mathrm{M}$ phosphate buffered saline with $0.02 \%$ diethylpyrocarbonate 3 times for 3 minutes, $2 \times$ SSC for 3 minutes, a single dipping in deionized water, and dehydration by immersion in increasing concentrations of ethanol. Each brain slice was hybridized with $30 \mu \mathrm{l}$ hybridization buffer under a coverslip to prevent tissue drying and then incubated in a high-humidity environment overnight at $36-42^{\circ} \mathrm{C}$. After hybridization, coverslips were carefully removed by floating them off in $1 \times$ SSC. The slices were rinsed in $1 \times$ SSC three times for 3 minutes each to remove excess hybridization buffer. The slides were then washed four times, 15 minutes each, in $2 \times \mathrm{SSC}+50 \%$ formamide at $46-52^{\circ} \mathrm{C}$, followed by two 30 minute washes in $1 \times$ SSC at room temperature. Finally, the slides were briefly dipped in deionized water and dried under cold dry air. Competition hybridization was carried out in the presence of 100 -fold excess unlabelled probe, which showed negligible non-specific hybridization in the final image.

\section{Analysis of Brain Imaging}

Slides of in situ hybridization and a 14C calibration standard (ARC-146C; ARC, St. Louis, MO) were apposed to ßmax film (Amersham, Arlington Heights, 
MI) at $4^{\circ} \mathrm{C}$ for three weeks. The films were analyzed using a computer-assisted image analysis system $(\mathrm{NIH}-$ Image program Ver. 1.62, Bethesda, MD) after scanning the films using a color scanner ES 3000 (EPSON Co., Tokyo, Japan). Serial sets of adjacent sections from six to nine animals for each treatment group were used for quantitative analysis. The standards included on each film exposure were also scanned and a standards curve was prepared. The average measured densities were converted to $\mathrm{nCi} / \mathrm{mg}$ for further analysis.

Experiments were carried out using horizontal sections of rat brain. MRNA of mGluRs was measured at the level of interaural $5.40 \mathrm{~mm}$, bregma $-4.60 \mathrm{~mm}$, and at the level of interaural $2.40 \mathrm{~mm}$, bregma $-7.60 \mathrm{~mm}$ according to the stereotaxic atlas of rat brain (Paxinos and Watson 1986). The measured brain areas were as follows; the anterior cingulate cortex, parietal cortex, temporal cortex, caudate-putamen, septal nucleus, thalamus (containing anterior, laterodorsal and lateral posteriol nuclei), hippocampus (CA1, CA2, CA3, dentate gyrus), central gray, inferior colliculus, nucleus accumbens, ventral pallidum, subiculum and entorhinal cortex. For mGluR2, by a reason of the specific laminar distribution in the cortex, we separately measured each layer of superficial, middle and deep in parietal and temporal cortices. The density in each region was recorded by positioning a circle cursor among $2-10$ areas over each region, or by outlining the border of regions on bilateral sides of the brain images, depending on the shape and size of the region examined.

\section{Data Analysis and Statistics}

Each value was the mean of duplicate determinations. The mean values were determined from 6-8 rats and expressed as the mean \pm SEM. The relative intensity of each mGluR subtype mRNA was determined as the ratio of the density of the image of treated animals to that of the control. The mean of the ratios for all controls was calculated and set at $100 \%$. Thus, results from each brain region of control and treated animals were expressed as a percentage of the value. Group differences in behavioral experiments were measured by analysis of variance (two-way ANOVA). In addition, significant differences in mRNA levels between the two groups were tested for each anatomical region separately using Mann-Whitney U test. In every case, the acceptable level for statistical significance was $p<.05$.

\section{RESULTS}

\section{Behavioral Analysis}

Figure 1 shows the locomotor activities of the rats treated chronically with PCP or saline over 14 days. Locomotor activities in PCP administrated rats were significantly increased 6- to 8-fold during PCP treatment $(p=$ $1.0 \times 10^{-23}$ vs. control group, $\mathrm{F}=3.99, \mathrm{n}=9$ ). $\mathrm{PCP}-$ induced stereotyped behaviors, including rearing and backpedaling, were observed, as seen in Figure 2. With a number of injections of $\mathrm{PCP}$, rearing was gradually increased $\left(p=3.8 \times 10^{-7}, \mathrm{~F}=2.95, \mathrm{n}=8\right)$, and backpedaling was gradually decreased $(p=.002, \mathrm{~F}=2.95, \mathrm{n}=8)$.

\section{In situ Hybridization}

The mRNA of each mGluR subtype was expressed in different discrete areas (Figure 3, Panels A-E), as previously described by Testa et al. (1994). We examined the 16 brain regions for mGluR1, 3, 4, and 5, and 12 brain regions for mGluR2 by reason of its specific laminar distribution in the cortex.

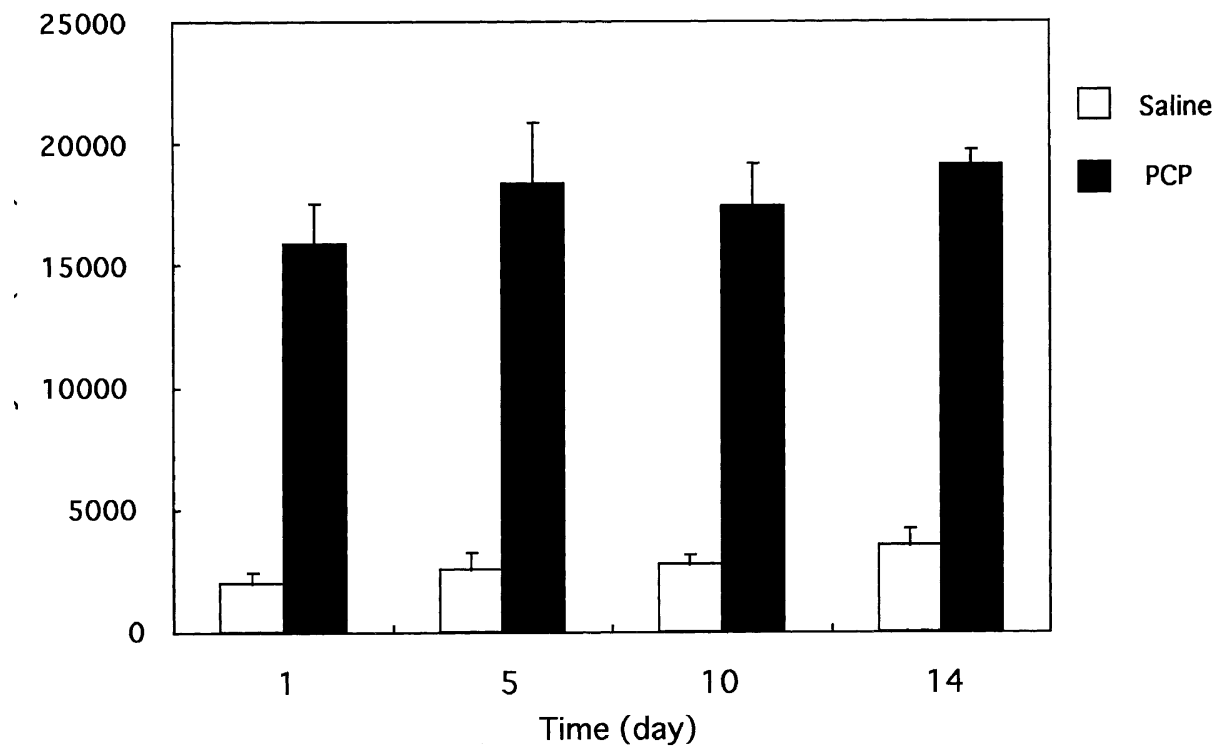

Figure 1. Locomotor activities of the rats treated with PCP (filled column) or saline (open column) over 14 days. Activity level represents the mean \pm standard error of 9 individual rats. Locomotor activities in PCP-administrated rats were significantly increased, 6 to 8-fold during PCP treatment $\left(p=1.0 \times 10^{-23}\right.$ vs. control group, $\mathrm{F}=3.99, \mathrm{n}=9$ ), measured by two-way ANOVA. 

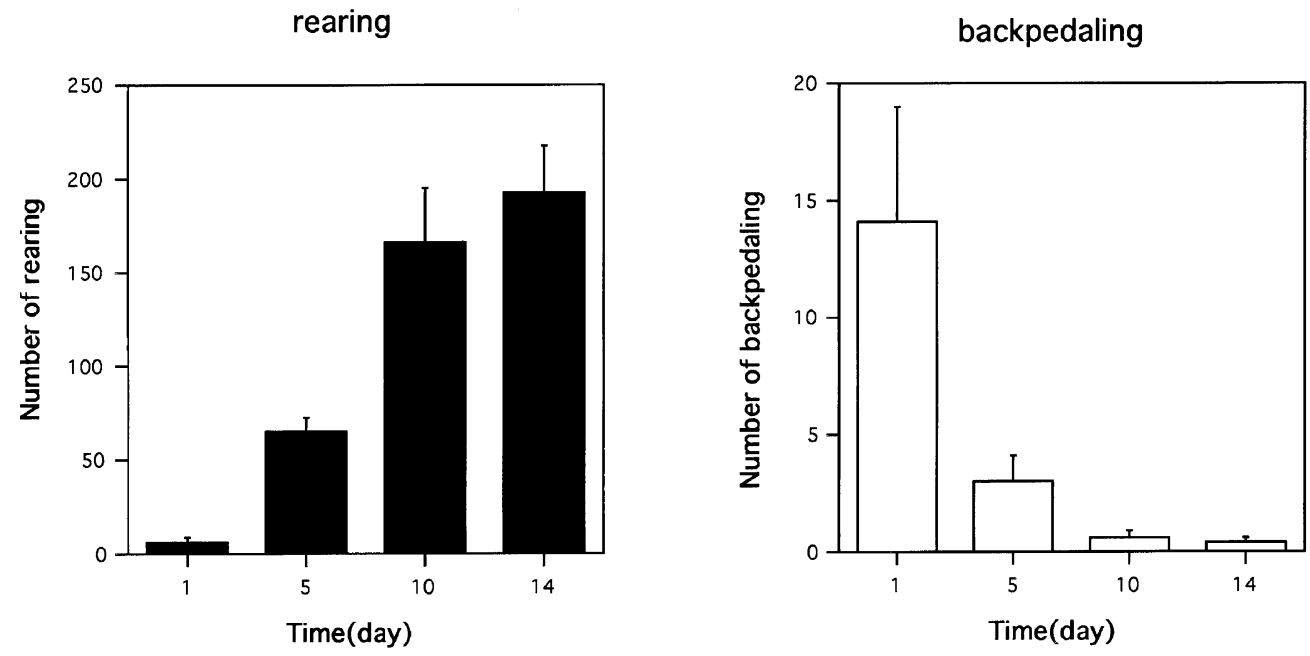

Figure 2. PCP-induced stereotyped behaviors, including rearing (left) and backpedaling (right) of rats treated chronically with PCP over 14 days. Each result represents the mean \pm S.E. of 6 individual rats. With a number of injections of PCP, rearing was gradually increased $\left(p=3.8 \times 10^{-7}, \mathrm{~F}=2.95, \mathrm{n}=8\right)$, and backpedaling was gradually decreased $(p=.002, \mathrm{~F}=2.95, \mathrm{n}=8)$, measured by one-way ANOVA.

Effects of One Hour after a Single Administration with PCP on the Expression of mGluR Subtype mRNAs. Table 1 shows the effects of acute administration of PCP on mGluR1, 3, 4, and 5 gene expressions in the 16 discrete areas of the rat brain. Table 2 shows the effects of both single and repeated administration of PCP on mGluR2 gene expression in the 12 discrete areas in the rat brain. A significant decrease in the levels of only mGluR5 mRNA was found in thalamus $(p=.002)$, CA1 $(p=.002)$, CA2 $(p=.01)$, CA3 $(p=.002)$, dentate gyrus $(p=.004)$, central gray $(p=.01)$, inferior colliculus $(p=$ .009 ) and accumbens $(p=.03)$, (see Figure 4) whereas no changes were observed in the expressions of mGluR1, 2, 3, and 4 after a single administration of PCP.

Effects of 24 Hours after Repeated Administration with PCP on the Expression of mGluR Subtype mRNAs. Table 3 shows the effects of chronic PCP administration on mGluR1, 3, 4, and 5 gene expressions in the 16 discrete areas in the rat brain. After repeated PCP administration over 14 days, the level of expression of mGluR2 mRNA in the anterior cingulate cortex $(p=.03)$ and of mGluR4 mRNA in the parietal $(p=.04)$, temporal $(p=$ $.03)$, and entorhinal $(p=.008)$ cortices, the caudate putamen $(p=.04)$, thalamus $(p=.04)$, and subiculum $(p=$ .02 ) were significantly decreased (see Figure 5). In contrast, no changes were observed in the level of mRNA of mGluR1, 3, and 5. Moreover, the mRNA of $\beta$-actin was distributed widely, but the level in PCP and control rats did not differ significantly in any brain region in either single or repeated PCP-administrated rats (data not shown).

Effects of 24 Hours after Single Administration with PCP on the Expression of mGluR Subtype mRNAs. Table 4 shows the effects of 24 hours after single administration of PCP on mGluR1, 3, 4, and 5 gene expressions in the 16 discrete areas of the rat brain. Table 2 shows the effects of 24 hours after single administration of PCP on mGluR2 gene expression in the 12 discrete areas in the rat brain. The level of mRNAs in PCP and control rats did not alter significantly in any subtype of mGluR and any brain region.

\section{DISCUSSION}

The major findings of the present study include the following: 1) A significant decrease was observed only in the mGluR5 mRNA expression of group I mGluR in a number of subcortical regions (thalamus, central gray, inferior colliculus, and nucleus accumbens) and hippocampal formation (CA1, CA2, CA3, and dentate gyrus) 1hr after a single PCP injection, 2) Repeated injections of PCP over 14 days caused significant decreases in the mGluR2 mRNA expression of group II mGluR in the anterior cingulate cortex and of mGluR4 mRNA of group III mGluR in the cortical regions (parietal, temporal, and entorhinal cortices), the caudate putamen, thalamus, and subiculum. Furthermore, the level of $\beta$-actin mRNA was not significantly altered in any brain region in either single or repeated PCP-administrated rats, suggesting that the above-mentioned significant changes indicate a modification of the receptor subunit mRNA itself.

Among these present findings, a rapid decrease in gene expression for mGluR5 mRNA was observed $1 \mathrm{hr}$ after a single injection of PCP. In general, the major pathway of gene regulation for mGluR is thought to be mediated by immediate early genes (IEGs), although the exact mechanisms underlying gene transcription for 

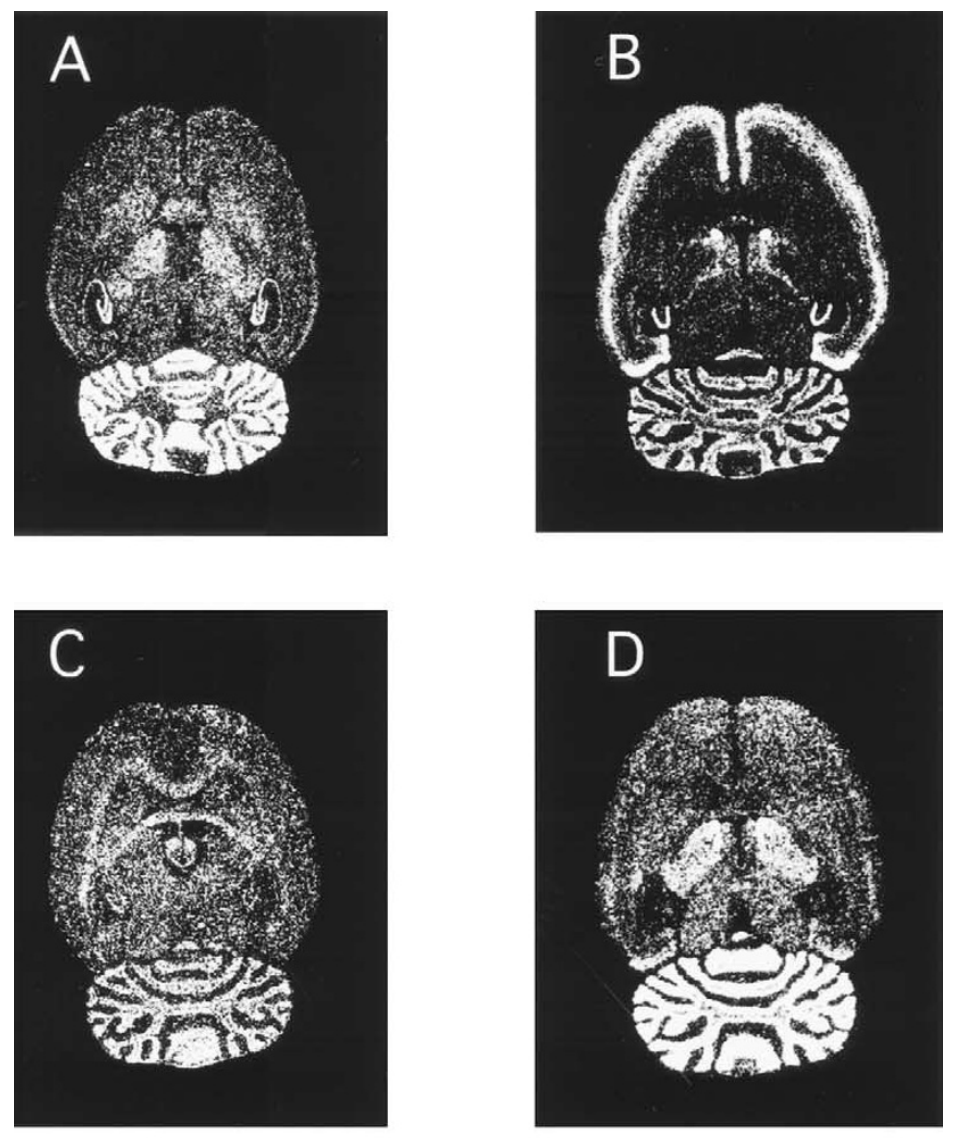

Figure 3. Distribution of mGluR subtype mRNAs of mGluR1 (Panel A), mGluR2 (Panel B), mGluR3 (Panel C), mGluR4 (Panel D) and mGluR5 (Panel E) in horizontal upper (interaural $5.4 \mathrm{~mm}$, bregma $-4.60 \mathrm{~mm}$ ) sections in rat brain.

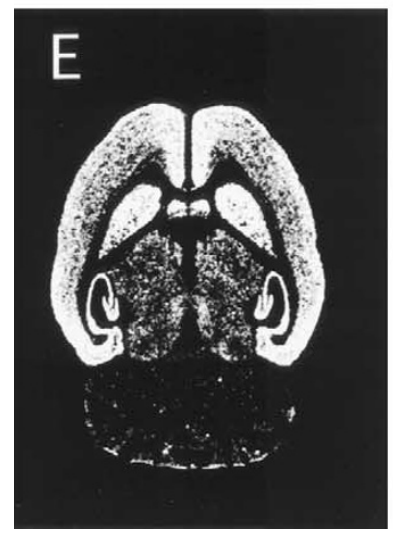

late response gene (LRG) remain unclear. Given that the occurrence of altered gene expression occurs at too early a stage to be responsible for the cellular response mediated by IEGs to external stimuli, a possible mechanism for the rapid change may be reflecting the changes in the turnover or stability of mGluR 5 mRNA.

\section{Decreased mRNA Levels of Group I mGluR after Single PCP Administration}

Recent studies have demonstrated that PCP and other non-competitive NMDA antagonists increase extracellular levels of glutamate in the prefrontal cortex and limbic regions (Adams and Moghaddam 1998; Moghaddam and Adams 1998). Several studies have suggested that increases in the synaptic availability of glutamate and in the postsynaptic activation of glutamate receptors may produce enhanced locomotion, stereotypy, and the subsequent activation of dopaminergic effects (Moghaddam and Adams 1998; Vezina and Kim 1999). As expected in the present study, the locomotion ratings of the PCP-treated rats significantly increased 8-fold in comparison to saline treated rats on the first day, suggesting an exacerbation of the glutamatergic and dopaminergic neural transmissions after a single injection of PCP. 

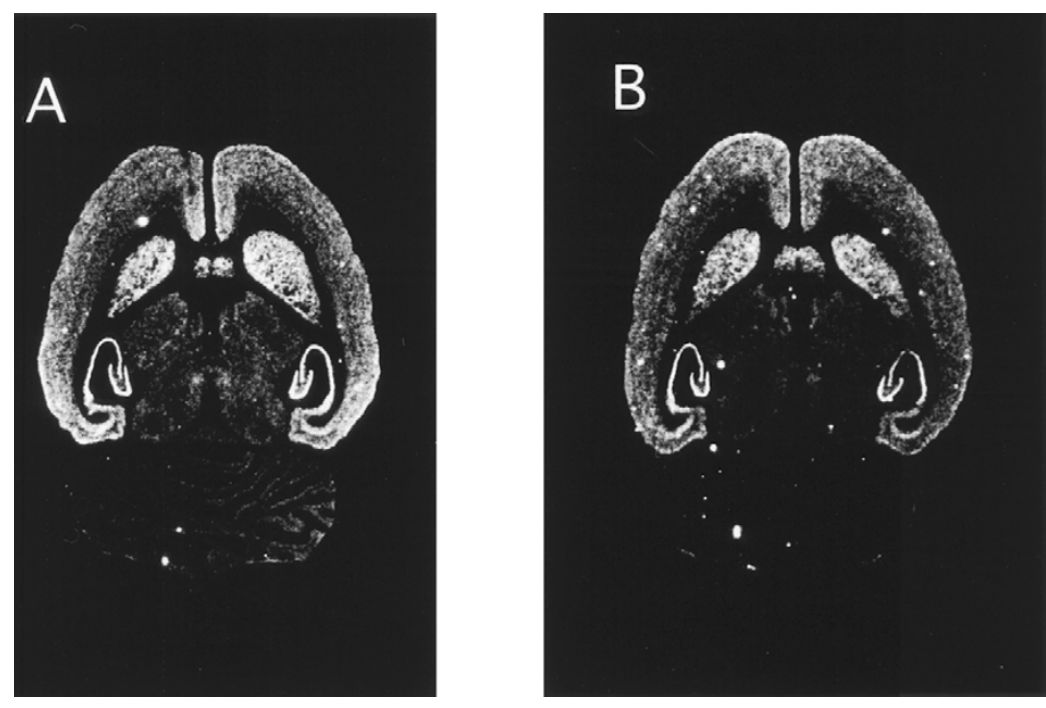

Figure 4. The autoradiogram of mGluR5 mRNA in horizontal upper (interaural $5.4 \mathrm{~mm}$, bregma $-4.60 \mathrm{~mm}$ ) sections in rat brain after single administration of saline (Panel A) and PCP (Panel B).
MGluRs can be subdivided into three groups according to their second messenger system and receptor pharmacology (see the introduction to this article). After a single PCP injection, a significant decrease was observed only in the mGluR5 mRNA expression of group I mGluR in subcortical regions (thalamus, central gray, inferior colliculus, and nucleus accumbens) and hippocampal formation (CA1, CA2, CA3, and dentate gyrus). Activation of group I mGluRs including mGluR1 and mGluR5 increases neural excitation predominantly via post-synaptic mechanisms (Nicoletti et al. 1996; Manzoni et al. 1997), although the expression of mGluR5 has been found in both presynapse and postsynapse. Therefore, the changes in mGluR $5 \mathrm{mRNA}$ levels after a single administration of PCP might indicate a compensatory decrease which does not mediate the excessive glutamatergic and dopaminergic neural transmissions induced by PCP treatment. Alternatively, recent reports have demonstrated a notable interaction between NMDA and mGluR5, in which activation of NMDA receptors reverse desensitized mGluR5 (Challiss et al. 1994; Alagarsamy et al. 1999). In the present study, this reciprocal regulation between two receptors may be associated with the decreased levels of mGluR5 mRNA induced by PCP, a non-competitive NMDA receptor antagonist.

\section{Decreased mRNA Levels of Group II and III mGluR after Repeated PCP Administration}

Both single and repeated administration of PCP in humans can induce hallucinations, delusions and cognitive dysfunction. Compared to single administration, repeated exposure of PCP generally more persistently manifests these symptoms and also causes flattened affect, amotivation and autism, which are considered to be core symptoms of schizophrenia (Javitt and Zukin 1991). Moreover, repeated exposure of PCP has been associated with reduced frontal lobe blood flow and glucose utilization (Hertzmann et al. 1990; Wu et al. 1991). These findings are consistent with the observations that some components of the cognitive dysfunction of schizophrenia are associated with reduced frontal blood flow and glucose utilization (Weinberger et al. 1986; Andreasen et al. 1992; Wolkin et al. 1992). Although it is premature to conclude that repeated PCP administration is superior to single PCP administration (Krystal et al. 1999), it is likely considered that repeated, but not single, administration of PCP more isomorphically models in several points of the behavioral and metabolic dysfunction of schizophrenia (Jentsch and Roth 1999).

The effects of repeated administration of PCP on basal extracellular levels of glutamate remain unclear. Previous studies have proved that repeated PCP exposure produces a functional hyperactivity of NMDA receptors in biochemical assay (Hanania et al. 1999) and electrophysiological recording (Arvanov and Wang 1999), which might be a homeostatic compensatory response to the prolonged reduction of basal glutamatergic transmission.

In the present study, repeated injections with PCP caused significant decreases in mGluR2 mRNA expression of group II mGluR in the anterior cingulate cortex and mGluR4 mRNA expression of group III mGluR in the cortical regions (parietal, temporal, and entorhinal cortices), the caudate putamen, thalamus, and subiculum. The alteration of mGluR2 mRNA expression of group II mGluR is consistent with several previous reports that the behavioral and neurochemical changes induced by PCP are related to the group II mGluR (Moghaddam and Adams 1998), especially mGluR2 (Spooren et al. 2000). Recently, several lines of evidence 

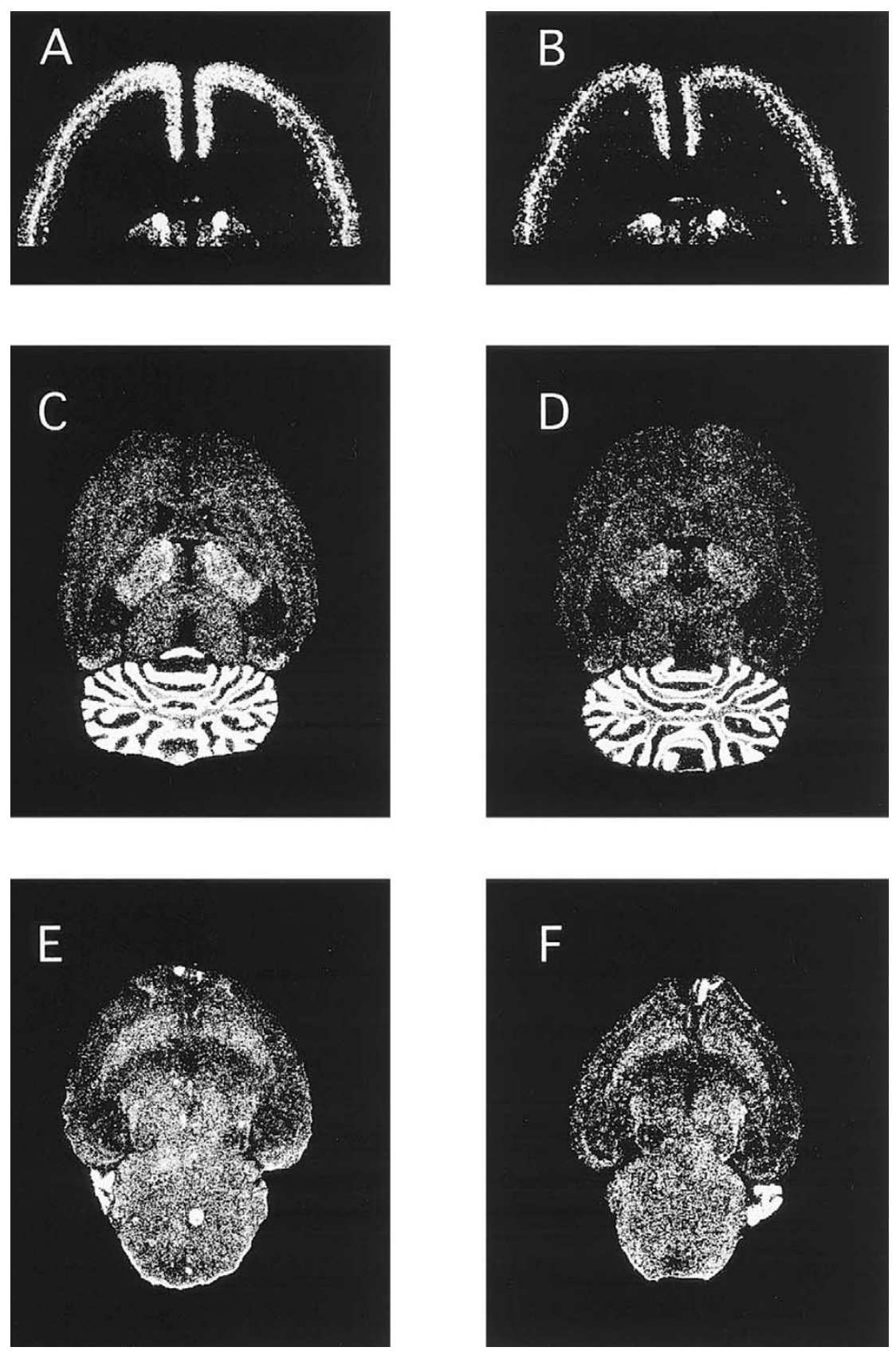

Figure 5. The autoradiograms of mRNA in horizontal upper (interaural $5.4 \mathrm{~mm}$, bregma $-4.60 \mathrm{~mm}$ ) or lower (interaural $2.4 \mathrm{~mm}$, bregma $-7.60 \mathrm{~mm}$ ) sections in rat brain after repeated administration. The following represents the subtype of mGluR, treatment and section level of each autoradiogram; Panel A: mGluR2 (Saline, upper); Panel B: mGluR2 (PCP, upper); Panel C: mGluR4 (Saline, upper); Panel D: mGluR4 (PCP, upper); Panel E: mGluR4 (Saline, lower); Panel F: mGluR4 (PCP, lower). have suggested that the functions of groups II and III mGluR have been presumed to inhibit the modulation of glutamate neural transmission by means of predominantly pre-synaptic mechanisms (Nicoletti et al. 1996; Battaglia et al. 1997; Manzoni et al. 1997). Taking into account the above observations, a down-regulation of the level of groups II and III mGluR mRNA may suggest a compensatory decrease, i.e., a disinhibition, to enhance glutamate release during the prolonged reduction of basal glutamatergic transmission after repeated administration of PCP. Moreover, in the behavioral study, PCP-induced stereotyped behavior, rearing, gradually increased with the number of $\mathrm{PCP}$ injections
(Figure 2). This implies the possibility that the disinhibition of group II and III mGluR and the functional hyperactivity of NMDA receptor results in the enhanced behavioral response to PCP injection in chronic PCPtreated rats.

Previous studies have revealed the abnormalities in the glutamatergic system of schizophrenics, including the decreased glutamate level in cerebrospinal fluid (Kim et al. 1980), decreased glutamate concentration prefrontal cortex and hippocampus (Tsai et al. 1995) the alterations of ionotropic glutamate receptor (Simpson et al. 1991; Meador-Woodruff and Healy 2000). As for mGluR, very little has been published examining this 
Table 1. Effects of $1 \mathrm{~h}$ after Single Administration with PCP on mGluR $(1,3,4,5)$ Receptor Gene Expression in Different Regions in Rat Brain

\begin{tabular}{lrccr}
\hline & mGluR1 & mGluR3 & mGluR4 & mGluR5 \\
\cline { 2 - 5 } & \multicolumn{4}{c}{ (\% of control level) } \\
\hline Anterior cingulate cortex & $110.6 \pm 5.4$ & $97.6 \pm 3.6$ & $96.3 \pm 4.7$ & $103.8 \pm 4.5$ \\
Parietal cortex & $102.5 \pm 6.1$ & $93.1 \pm 4.3$ & $94.6 \pm 2.4$ & $96.3 \pm 2.2$ \\
Temporal cortex & $102.6 \pm 6.0$ & $92.1 \pm 3.4$ & $96.0 \pm 1.8$ & $91.4 \pm 2.9$ \\
Caudate putamen & $108.1 \pm 5.0$ & $94.2 \pm 4.3$ & $102.5 \pm 1.8$ & $96.5 \pm 2.4$ \\
Septal nucleus & $93.0 \pm 6.0$ & $93.9 \pm 3.2$ & n.d. & $102.3 \pm 7.5$ \\
Thalamus & $112.8 \pm 7.0$ & $97.1 \pm 2.7$ & $98.5 \pm 1.7$ & $85.4 \pm 1.6^{* *}$ \\
CA1 & $107.0 \pm 5.9$ & n.d. & n.d. & $85.6 \pm 1.3^{* *}$ \\
CA2 & $93.7 \pm 5.6$ & n.d. & n.d. & $84.8 \pm 2.2^{*}$ \\
CA3 & $94.7 \pm 1.0$ & n.d. & n.d. & $82.1 \pm 2.5^{* *}$ \\
Dentate gyrus & $92.0 \pm 5.5$ & n.d. & n.d. & $81.5 \pm 2.9^{* *}$ \\
Central gray & $94.4 \pm 5.9$ & $98.9 \pm 3.9$ & $93.3 \pm 1.9$ & $76.6 \pm 4.4^{*}$ \\
Inferior colliculus & $103.3 \pm 6.4$ & $98.7 \pm 3.3$ & $92.4 \pm 3.9$ & $76.9 \pm 4.9^{* *}$ \\
Accumbens & $108.4 \pm 2.4$ & $95.1 \pm 2.7$ & $107.9 \pm 4.0$ & $89.8 \pm 2.8^{*}$ \\
Ventral pallidum & $105.5 \pm 3.3$ & n.d. & n.d. & $93.1 \pm 4.7$ \\
Subiculum & $99.0 \pm 2.9$ & $96.9 \pm 4.8$ & $109.0 \pm 3.0$ & $87.8 \pm 4.5$ \\
Entorhinal cortex & $91.3 \pm 2.9$ & $94.1 \pm 5.2$ & $105.7 \pm 3.5$ & $88.5 \pm 5.4$ \\
\hline
\end{tabular}

Rats were injected with PCP $(7.5 \mathrm{mg} / \mathrm{kg}$, i.p.) and sacrificed $1 \mathrm{~h}$ after a single injection. The results, expressed as percentage of saline-injected rats represent the mean \pm standard error of 8 individual rats. ${ }^{*} p<$ $.05,{ }^{* *} p<.01$, vs. control rats (Mann-Whitney U test). n.d. = not detectable.

family of receptors in schizophrenic brain. Ohnuma et al. demonstrated that the mRNA encoding of mGluR5, but not mGluR3, was increased in the orbitofrontal cortex. Cell-level analysis revealed that this increase was due to increased expression of mGluR5 mRNA in pyramidal cells in lamina III (Ohnuma et al. 1998). Recent report examined the levels of mRNA of mGluR1, 2, 3, 4, 5, 7 , and 8 in thalamus, but failed to show significant changes (Richardson-Bruns et al. 1999). In using a method of recent neurochemical imaging, the discovery of the hypofunction of glutamatergic system in this illness has been confirmed by magnetic resonance spectroscopy (MRS) studies (Bartha et al. 1997).

Although the levels of mRNAs may not always correspond to the amount of their proteins, the data obtained in the present study may help in understanding

Table 2. Effects of Single and Repeated Administration with PCP on mGluR2 Receptor Gene Expression in Different Regions in Rat Brain

\begin{tabular}{|c|c|c|c|}
\hline & \multicolumn{2}{|c|}{ Single } & \multirow[t]{2}{*}{ Repeated } \\
\hline & $1 \mathrm{~h}$ & $24 \mathrm{~h}$ & \\
\hline & \multicolumn{3}{|c|}{ (\% of control level) } \\
\hline Anterior cingulate cortex & $100.5 \pm 11.6$ & $106.6 \pm 5.5$ & $77.0 \pm 5.5^{*}$ \\
\hline \multicolumn{4}{|l|}{ Parietal cortex } \\
\hline (layer II/III) & $99.4 \pm 8.1$ & $102.6 \pm 3.8$ & $91.9 \pm 5.7$ \\
\hline (layer IV) & $91.5 \pm 8.4$ & $111.7 \pm 6.9$ & $103.4 \pm 11.0$ \\
\hline (layer V/VI) & $91.0 \pm 7.3$ & $110.4 \pm 5.6$ & $104.2 \pm 6.3$ \\
\hline \multicolumn{4}{|l|}{ Temporal cortex } \\
\hline (layer II/III) & $91.5 \pm 6.3$ & $107.8 \pm 5.1$ & $93.6 \pm 5.9$ \\
\hline (layer IV) & $94.0 \pm 8.5$ & $108.3 \pm 5.7$ & $100.7 \pm 10.7$ \\
\hline (layer V/VI) & $91.0 \pm 8.1$ & $107.9 \pm 3.9$ & $95.9 \pm 5.3$ \\
\hline Thalamus & $91.1 \pm 5.9$ & $106.3 \pm 3.6$ & $97.0 \pm 4.5$ \\
\hline Dentate gyrus & $92.0 \pm 2.6$ & $104.7 \pm 2.9$ & $101.2 \pm 3.9$ \\
\hline Accumbens & $95.4 \pm 7.7$ & $96.7 \pm 7.2$ & $92.4 \pm 4.0$ \\
\hline Subiculum & $107.7 \pm 7.7$ & $104.9 \pm 7.8$ & $105.2 \pm 8.7$ \\
\hline Entorhinal cortex & $94.2 \pm 6.9$ & $95.7 \pm 2.8$ & $105.2 \pm 11.7$ \\
\hline
\end{tabular}

Rats were injected with PCP $(7.5 \mathrm{mg} / \mathrm{kg}$, i.p.). The rats of single administration were decapitated $1 \mathrm{~h}$ and $24 \mathrm{~h}$ after a single injection. The rats of repeated administration were decapitated $24 \mathrm{~h}$ after the last injection of successive 14 days treatment. The results, expressed as percentage of saline-injected rats represent the mean \pm standard error of 8 individual rats. ${ }^{*} p<.05$, vs. control rats (Mann-Whitney U test). n.d. $=$ not detectable. 
Table 3. Effects of Repeated Administration with PCP on mGluR $(1,3,4,5)$ Receptor Gene Expression in Different Regions in Rat Brain

\begin{tabular}{lcccr}
\hline & mGluR1 & mGluR3 & mGluR4 & mGluR5 \\
\cline { 2 - 5 } & \multicolumn{4}{c}{ (\% of control level) } \\
\hline Anterior cingulate cortex & $110.4 \pm 3.2$ & $97.9 \pm 3.6$ & $92.4 \pm 3.2$ & $95.2 \pm 4.4$ \\
Parietal cortex & $110.5 \pm 4.8$ & $99.6 \pm 2.6$ & $88.6 \pm 2.9^{*}$ & $95.4 \pm 3.6$ \\
Temporal cortex & $106.4 \pm 5.2$ & $100.5 \pm 3.3$ & $86.5 \pm 3.9^{*}$ & $96.4 \pm 3.9$ \\
Caudate putamen & $109.7 \pm 5.1$ & $102.0 \pm 3.9$ & $87.9 \pm 2.9^{*}$ & $92.3 \pm 3.4$ \\
Septal nucleus & $99.2 \pm 7.0$ & $98.5 \pm 2.5$ & n.d. & $91.6 \pm 3.8$ \\
Thalamus & $104.3 \pm 4.5$ & $99.8 \pm 2.7$ & $83.3 \pm 4.4^{*}$ & $95.0 \pm 4.0$ \\
CA1 & $92.89 \pm 5.0$ & n.d. & n.d. & $93.0 \pm 2.8$ \\
CA2 & $106.8 \pm 4.5$ & n.d. & n.d. & $99.5 \pm 4.0$ \\
CA3 & $100.3 \pm 4.3$ & n.d. & n.d. & $93.1 \pm 3.8$ \\
Dentate gyrus & $101.1 \pm 5.8$ & n.d. & n.d. & $93.3 \pm 5.0$ \\
Central gray & $108.8 \pm 3.5$ & $102.3 \pm 3.3$ & $90.2 \pm 3.9$ & $100.3 \pm 4.3$ \\
Inferior colliculus & $100.2 \pm 4.71$ & $101.6 \pm 2.6$ & $87.3 \pm 3.2$ & $98.4 \pm 1.7$ \\
Accumbens & $100.4 \pm 3.6$ & $107.5 \pm 1.6$ & $96.0 \pm 5.9$ & $100.9 \pm 2.2$ \\
Ventral pallidum & $104.2 \pm 3.2$ & n.d. & n.d. & $102.8 \pm 3.4$ \\
Subiculum & $92.8 \pm 3.4$ & $102.6 \pm 2.0$ & $74.9 \pm 4.5^{*}$ & $91.4 \pm 3.3$ \\
Entorhinal cortex & $95.0 \pm 3.8$ & $102.8 \pm 2.8$ & $81.7 \pm 3.1^{* *}$ & $106.5 \pm 9.2$ \\
\hline
\end{tabular}

Rats were injected for 14 days with PCP $(7.5 \mathrm{mg} / \mathrm{kg}$, i.p.) and sacrificed $24 \mathrm{~h}$ after the last injection. The results, expressed as percentage of saline-injected rats represent the mean \pm standard error of 8 individual rats. ${ }^{*} p<.05,{ }^{* *} p<.01$, vs. control rats (Mann-Whitney U test). n.d. = not detectable.

the mechanisms underlying the adaptive response to prolonged reduction in glutamatergic transmission that has been postulated to be a pathophysiology of schizophrenia.

In summary, a single PCP administration resulted in a significant decrease in the mGluR5 mRNA expression of group I mGluR, whereas significant decreases in the mGluR2 mRNA expression of group II mGluR and the mGluR4 mRNA expression of group III mGluR were observed in a region-specific manner after repeated
PCP administration. Further investigations in this area and the development of selective radioligands for each group of mGluR are needed to clarify a functional significance of each group of mGluR and the amounts of the receptor proteins. However, our results indicate that PCP affects not only group II but also group I and III of mGluR mRNA, and it is of particular interest that mGluR2 subtype is involved in a development of behavioral abnormality following repeated PCP administration. The different regulations of mGluR subtypes of

Table 4. Effects of $24 \mathrm{~h}$ after Single Administration with PCP on mGluR $(1,3,4,5)$ Receptor Gene Expression in Different Regions in Rat Brain

\begin{tabular}{lcccr}
\hline & mGluR1 & mGluR3 & mGluR4 & mGluR5 \\
\cline { 2 - 5 } & \multicolumn{4}{c}{ (\% of control level) } \\
\hline Anterior cingulate cortex & $100.8 \pm 5.9$ & $102.3 \pm 6.4$ & $106.1 \pm 7.6$ & $91.9 \pm 6.3$ \\
Parietal cortex & $109.0 \pm 3.1$ & $106.6 \pm 9.0$ & $108.5 \pm 5.6$ & $92.6 \pm 4.4$ \\
Temporal cortex & $104.1 \pm 3.2$ & $112.7 \pm 4.1$ & $104.1 \pm 5.6$ & $99.1 \pm 3.8$ \\
Caudate putamen & $110.0 \pm 3.6$ & $105.3 \pm 7.8$ & $105.4 \pm 8.0$ & $96.9 \pm 8.8$ \\
Septal nucleus & $103.9 \pm 7.0$ & $110.7 \pm 4.1$ & n.d. & $91.6 \pm 6.6$ \\
Thalamus & $111.7 \pm 3.2$ & $109.5 \pm 9.3$ & $102.5 \pm 10.4$ & $91.7 \pm 6.5$ \\
CA1 & $112.2 \pm 5.9$ & n.d. & n.d. & $101.2 \pm 4.8$ \\
CA2 & $109.9 \pm 3.9$ & n.d. & n.d. & $97.8 \pm 6.5$ \\
CA3 & $112.6 \pm 3.8$ & n.d. & n.d. & $94.7 \pm 4.6$ \\
Dentate gyrus & $105.5 \pm 4.3$ & n.d. & n.d. & $92.9 \pm 2.5$ \\
Central gray & $111.9 \pm 5.4$ & $112.1 \pm 7.6$ & $106.1 \pm 7.9$ & $96.2 \pm 5.5$ \\
Inferior colliculus & $112.8 \pm 6.2$ & $108.2 \pm 8.4$ & $97.9 \pm 6.8$ & $97.3 \pm 7.4$ \\
Accumbens & $104.1 \pm 1.9$ & $109.1 \pm 7.2$ & $92.2 \pm 2.9$ & $92.3 \pm 4.4$ \\
Ventral pallidum & $106.5 \pm 4.9$ & n.d. & n.d. & $90.5 \pm 5.3$ \\
Subiculum & $109.8 \pm 10.2$ & $110.0 \pm 6.9$ & $97.4 \pm 3.2$ & $101.2 \pm 4.1$ \\
Entorhinal cortex & $111.1 \pm 7.7$ & $104.6 \pm 4.9$ & $93.8 \pm 3.1$ & $94.4 \pm 1.6$ \\
\hline
\end{tabular}

Rats were injected with PCP $(7.5 \mathrm{mg} / \mathrm{kg}$, i.p.) and sacrificed $24 \mathrm{~h}$ after a single injection. The results, expressed as percentage of saline-injected rats represent the mean \pm standard error of 6 individual rats. 
mRNA after single and repeated PCP administration were discussed in view of the differences of the activity of putative glutamatergic neural transmission.

\begin{abstract}
Abbreviations
PCP, phencyclidine; mGluR, metabotropic glutamate receptor; NMDA, N-methyl-D-aspartate; GABA, $\gamma$-aminobutyric acid; CNS, central nervous system; i.p., intraperitoneal; SSC, sodium chloride-sodium citrate buffer; IEG, immediate early gene; LRG, late response gene; MRS, magnetic resonance spectroscopy
\end{abstract}

\section{ACKNOWLEDGMENTS}

This study was supported in part by a Grant-in-Aid for Scientific Research(C) 08671072 from the Ministry of Education, Science and Culture to TS.

\section{REFERENCES}

Abe S, Suzuki T, Ito T, Baba A, Hori T, Kurita H, Yamaguchi M, Shiraishi H (2000): Differential expression of $\mathrm{GABA}_{A}$ receptor subunit $m R N A s$ and ligand binding sites in rat brain following phencyclidine administration. Synapse 38: $51-60$

Adams B, Moghaddam B (1998): Corticolimbic dopamine neurotransmission is temporally dissociated from the cognitive and locomotor effects of phencyclidine. J Neurosci 18:5545-5554

Alagarsamy S, Marino MJ, Rouse ST, Gereau 4th RW, Heinemann SF, Conn PJ (1999): Activation of NMDA receptors reverses desensitization of mGluR5 in native and recombinant systems. Nat Neurosci 2:234-240

Andreasen NC, Rezai K, Alliger R, Swayze 2d VW, Flaum M, Kirchner P, Cohen G, O'Leary DS (1992): Hypofrontality in neuroleptic-naive patients and in patients with chronic schizophrenia. Assessment with xenon 133 single-photon emission computed tomography and the Tower of London. Arch Gen Psychiatry 49:943-958

Arvanov VL, Wang RY (1999): Clozapine, but not haloperidol, prevents the functional hyperactivity of N-methyl$\mathrm{D}$-aspartate receptors in rat cortical neurons induced by subchronic administration of phencyclidine. J Pharmacol Exp Ther 289:1000-1006

Bartha R, Williamson PC, Drost DJ, Malla A, Carr TJ, Cortese L, Canaran G, Rylett RJ, Neufeld RW (1997): Measurement of glutamate and glutamine in the medial prefrontal cortex of never-treated schizophrenic patients and healthy controls by proton magnetic resonance spectroscopy. Arch Gen Psychiatry 54:959-965

Battaglia G, Monn JA, Schoepp DD (1997): In vivo inhibition of veratridine-evoked release of striatal excitatory amino acids by the group II metabotropic glutamate receptor agonist LY354740 in rats. Neurosci Lett 229: 161-164

Carlsson M, Carlsson A (1990): Schizophrenia: a subcortical neurotransmitter imbalance syndrome? Schizophr Bull $16: 425-32$
Cartmell J, Monn JA, Schoepp DD (1999): The metabotropic glutamate 2/3 receptor agonists LY354740 and LY379268 selectively attenuate phencyclidine versus damphetamine motor behaviors in rats. J Pharmacol Exp Ther 291:161-170

Cartmell J, Monn JA, Schoepp DD (2000): Tolerance to the motor impairment, but not to the reversal of PCPinduced motor activities by oral administration of the mGlu2/3 receptor agonist, LY379268. Naunyn Schmiedebergs Arch. Pharmacol 361:39-46

Castellani S, Adams PM (1981): Acute and chronic phencyclidine effects on locomotor activity, stereotypy and ataxia in rats. Eur J Pharmacol 73:143-154

Challiss RA, Mistry R, Gray DW, Nahorski SR (1994): Modulatory effects of NMDA on phosphoinositide responses evoked by the metabotropic glutamate receptor agonist 1S,3R-ACPD in neonatal rat cerebral cortex. Br J Pharmacol 112:231-239

Conn PJ, Pin JP (1997): Pharmacology and functions of metabotropic glutamate receptors. Annu Rev Pharmacol Toxicol 37:205-237

Cozzi A, Attucci S, Peruginelli F, Marinozzi M, Luneia R, Pellicciari R, Moroni F (1997): Type 2 metabotropic glutamate (mGlu) receptors tonically inhibit transmitter release in rat caudate nucleus: in vivo studies with (2S,1'S,2'S,3'R)-2-(2'-carboxy-3'-phenylcyclopropyl)glycine, a new potent and selective antagonist. Eur J Neurosci 9:1350-1355

Csernansky JG, Joshi S, Wang L, Haller JW, Gado M, Miller JP, Grenander U, Miller MI (1998): Hippocampal morphometry in schizophrenia by high dimensional brain mapping. Proc Natl Acad Sci U S A 95:11406-11411

Di Iorio P, Battaglia G, Ciccarelli R, Ballerini P, Giuliani P, Poli A, Nicoletti F, Caciagli F (1996): Interaction between A1 adenosine and class II metabotropic glutamate receptors in the regulation of purine and glutamate release from rat hippocampal slices. J Neurochem 67:302-309

East SJ, Hill MP, Brotchie JM (1995): Metabotropic glutamate receptor agonists inhibit endogenous glutamate release from rat striatal synaptosomes. Eur J Pharmacol 277:117-121

Fotuhi M, Standaert DG, Testa CM, Penney Jr JB, Young AB (1994): Differential expression of metabotropic glutamate receptors in the hippocampus and entorhinal cortex of the rat. Mol Brain Res 21:283-292

Greenamyre JT, Porter RH (1994): Anatomy and physiology of glutamate in the CNS. Neurology 44:S7-S13.

Hanania T, Hillman GR, Johnson KM (1999): Augmentation of locomotor activity by chronic phencyclidine is associated with an increase in striatal NMDA receptor function and an upregulation of the NR1 receptor subunit. Synapse 31:229-239

Heckers S, Rauch SL, Goff D, Savage CR, Schacter DL, Fischman AJ, Alpert NM (1998): Impaired recruitment of the hippocampus during conscious recollection in schizophrenia. Nat Neurosci 1998 1:318-323

Hertzmann M, Reba RC, Kotlyarov EV (1990): Single photon emission computed tomography in phencyclidine and related drug abuse. Am J Psychiatry 147:255-256

Javitt DC, Zukin SR (1991): Recent advances in the phencyc- 
lidine model of schizophrenia. Am J Psychiatry 148: 1301-1308

Jentsch JD, Redmond Jr DE, Elsworth JD, Taylor JR, Youngren KD, Roth RH (1997): Enduring cognitive deficits and cortical dopamine dysfunction in monkeys after long-term administration of phencyclidine. Science 277:953-955

Jentsch JD, Roth RH (1999): The neuropsychopharmacology of phencyclidine: from NMDA receptor hypofunction to the dopamine hypothesis of schizophrenia. Neuropsychopharmacology 20:201-225

Kim JS, Kornhuber HH, Schmid-Burgk W, Holzmuller B (1980): Low cerebrospinal fluid glutamate in schizophrenic patients and a new hypothesis of schizophrenia. Neuorsci Lett 20:379-382

Krystal JH, Belger A, D'Souza DC, Anand A, Charney DS, Aghajanian GK, Moghaddam B (1999): Therapeutic implications of the hyperglutamatergic effects of NMDA antagonists. Neuropsychopharmacology 22:S143-157

Lovinger DM, McCool BA (1995): Metabotropic glutamate receptor-mediated presynaptic depression at corticostriatal synapses involves mGLuR2 or 3. J Neurophysiol 73:1076-1083

Manzoni O, Michel JM, Bockaert J (1997): Metabotropic glutamate receptors in the rat nucleus accumbens. Eur J Neurosci 9:1514-1523

Martin G, Nie Z, Siggins GR (1997): Metabotropic glutamate receptors regulate $\mathrm{N}$-methyl-D-aspartate-mediated synaptic transmission in nucleus accumbens. J Neurophysiol 78:3028-3038

Meador-Woodruff JH, Healy DZJ (2000): Glutamate receptor expression in schizophrenic brain. Brain Res Rev 31: 288-294

Moghaddam B, Adams BW (1998): Reversal of phencyclidine effects by a group II metabotropic glutamate receptor agonist in rats. Science 281:1349-1352

Nabeshima T, Fukaya H, Yamaguchi K, Ishikawa K, Furukawa H, Kameyama T (1987): Development of tolerance and supersensitivity to phencyclidine in rats after repeated administration of phencyclidine. Eur J Pharmacol 135:23-33

Nicoletti F, Bruno V, Copani A, Casabona G, Knopfel T (1996): Metabotropic glutamate receptors: a new target for the therapy of neurodegenerative disorders? Trends Neurosci 19:267-271

Ohnuma T, Augood SJ, Arai H, McKenna PJ, Emson PC (1998): Expression of the human excitatory amino acid transporter 2 and metabotropic glutamate receptors 3 and 5 in the prefrontal cortex from normal individuals and patients with schizophrenia. Mol Brain Res 56:207-217

Paxinos G, Watson C (1986): The Rat Brain in Stereotaxic Coordinates, 2nd ed. New York, Academic Press

Ponte P, Ng SY, Engel J, Gunning P, Kedes L (1984): Evolu- tionary conservation in the untranslated regions of actin mRNAs: DNA sequence of a human beta-actin cDNA. Nucleic Acids Res 12:1687-1696

Richardson-Bruns SM, Haroutunian V, Davis KL, Watson SJ, Meador-Woodruff JH (1999): Metabotropic glutamate receptor mRNA expression in schizophrenic thalamus. Biol Psychiatry 47:22-28

Simpson MD, Slater P, Royston MC, Deakin JF (1991): Alterations in phencyclidine and sigma binding sites in schizophrenic brains. Effects of disease process and neuroleptic medication. Schizophr Res 6:41-48

Spooren WP, Gasparini F, van der Putten H, Koller M, Nakanishi S, Kuhn R (2000): Lack of effect of LY314582 (a group 2 metabotropic glutamate receptor agonist) on phencyclidine-induced locomotor activity in metabotropic glutamate receptor 2 knockout mice. Eur J Pharmacol 397:R1-2

Stevens JR (1973): An anatomy of schizophrenia. Arch Gen Psychiatry 29: 177-189.

Sturgeon RD, Fessler RG, Meltzer HY (1979): Behavioral rating scales for assessing phencyclidine-induced locomotor activity, stereotyped behavior and ataxia in rats. Eur J Pharmacol 59:169-179

Tamminga CA (1998): Schizophrenia and glutamatergic transmission. Crit Rev Neurobiol 12:21-36

Testa CM, Standaert DG, Young AB, Penney JB Jr (1994): Metabotropic glutamate receptor mRNA expression in the basal ganglia of the rat. J Neurosci 14:3005-3018

Tsai G, Passani LA, Slusher BS, Carter R, Baer L, Kleinman JE, Coyle JT (1995): Abnormal excitatory neurotransmitter metabolism in schizophrenic brains. Arch Gen Psychiatry 52:829-836

Vezina P, Kim JH (1999): Metabotropic glutamate receptors and the generation of locomotor activity: interactions with midbrain dopamine. Neurosci Biobehav Rev 23: $577-589$

Weinberger DR, Berman KF, Zec RF (1986): Physiologic dysfunction of dorsolateral prefrontal cortex in schizophrenia. I. Regional cerebral blood flow evidence. Arch Gen Psychiatry 43:114-124

Weinberger DR, Berman KF, Suddath R, Torrey EF (1992): Evidence of dysfunction of a prefrontal-limbic network in schizophrenia: a magnetic resonance imaging and regional cerebral blood flow study of discordant monozygotic twins. Am J Psychiatry 149:890-897

Wolkin A, Sanfilipo M, Wolf AP, Angrist B, Brodie JD, Rotrosen J (1992): Negative symptoms and hypofrontality in chronic schizophrenia. Arch. Gen. Psychiatry 49: 959-965

Wu JC, Buchsbaum MS, Bunney WE (1991): Positron emission tomography study of phencyclidine users as a possible drug model of schizophrenia. Jpn J Psychopharmacol 11:47-48 